\title{
A REVIEW OF PATTERN OF HEAD AND NECK MALIGNANGIES SEEN IN SOKOTO, NIGERIA BETWEEN 2005 and 2010
}

\author{
Abdullahi $\mathbf{M}^{1}$, Sahabi SMㄹ, Iseh KR ${ }^{1}$, Amutta SB ${ }^{1}$, Aliyu $\mathbf{D}^{1}$ \\ Departments of Otorhinolaryngology ${ }^{1}$ and Histopathology ${ }^{2}$, Usmanu Danfodiyo University Teaching Hospital, Sokoto, Nigeria \\ Correspondence: Dr. M. Abdullahi \\ Department of Otorhinolaryngology, Usmanu Danfodiyo University Teaching Hospital, Sokoto \\ P.M.B 2370 Sokoto State Nigeria. E-mail: mabdullahi7174@gmail.com
}

\section{ABSTRACT}

\section{BACKGROUND}

Head and neck cancers have a global burden and are more burdensome especially in the developing countries where risk factors, late presentation and low socioeconomic status still predominate.

\section{OBJECTIVE}

To determine any change in the pattern of head and neck cancers in the Usmanu Danfodiyo University Teaching Hospital, Sokoto after 5 years.

\section{METHOD}

This is a retrospective five year study (2005-2010) of 146 histologically diagnosed head and neck cancers from the registers of the department of histopathology.

\section{RESULTS}

One hundred and forty six head and neck cancer patients were studied representing $18.6 \%$ of the total number of 787 histologically diagnosed malignancies during the study period (2005-2010). There were 93 males (63.7\%) and 53 female (36.3\%). The male to female ratio was 1.8:1. The ages of patients ranged from3-89 years with the mean age of 41.6 \pm 20.5 years. The highest number of patients was seen in the $5^{\text {th }}$ decade $(21.2 \%)$ of life. There were $112(76.7 \%)$ carcinomas, $20(13.7 \%)$ lymphomas, $5(3.4 \%)$ sarcomas and $9(6.2 \%)$ blastomas. Seventy cases (47.9\%) were head and neck squamous cell carcinoma. Sinonasal carcinoma 24(16.4\%) was the commonest Head and neck cancer. Retinoblastoma 5(3.4\%) was the commonest childhood head and neck cancer.

\section{CONCLUSION}

There was no significant change in the pattern of the head and neck cancers $(P>0.05)$. Sinonasal cancinoma was the commonest head and neck malignant tumour. Head and cancers still remains a challenge in this region.

Keywords: Head and neck, Cancer, Sokoto, Nigeria.

\section{INTRODUCTION}

Head and neck cancers consist of malignant tumors arising within the upper aero-digestive tract; every tissue type is represented in the head and neck: from skin to bony paranasal sinuses, salivary gland to lymphoid tonsil, and laryngeal cartilage and joints to pharyngeal epithelium ${ }^{1}$.

Head and neck cancers have a global burden ${ }^{2,3,4}$ and it is rated the $6^{\text {th }}$ most common type of cancer representing about $6 \%$ of all cases and accounting for an estimated 650,000 new cancer and 350,000 cancer deaths worldwide every year and two third of these occurring in the developing conutries ${ }^{2}$.

Any anatomical site can be affected by head and neck cancer ${ }^{4-11}$. Most of the cancers from these sites are squamous cell carcinoma ${ }^{1-12}$. Alcohol intake and cigarette smoking are well known risk factors which are implicated in $75 \%$ of squamous cell carcinoma of the head and neck and have a synergistic effect ${ }^{1,-3,5,10,11,14-17}$. However, there is increasing evidence in the past decades, of the role of HPV especially type 16 in the pathogenesis of head and neck cancers. The association of HPV and squamous cell carcinoma has potential implication for management of head and neck cancers. Hence, HPV status is an important predictive biomarker ${ }^{12}$.

The black populaces have a poorer prognosis compared to the white populace with 5 year survival being better in the later ${ }^{2,18}$.

Nigeria with a population of more than 140 million based on the 2006 population census ${ }^{19}$, regional hospital studies across the country ${ }^{3-7}$ ${ }^{9-11}$ have reported different patterns of head and neck cancer at various anatomic head and neck site with squamous cell carcinoma being the commonest histologic type.

Usmanu Danfodiyo University Teaching Hospital located in Sokoto, North western Nigeria, one of the major referring center from the neighboring states which may have an impact on the pattern of head and neck cancers seen in the institution. Previous studies in the same center on the pattern of head and neck cancers from 1999-2004 showed that nasopharyngeal carcinoma is the commonest head and neck cancer. Hence, the aim of this study is to determine any change in patterns of the head and neck malignancies in Sokoto, north western Nigeria after a five year period.

\section{MATERIALS AND METHODS}

This was a retrospective crosssectional study of head and neck malignancies from Usmanu Danfodiyo University Teaching Hospital, Sokoto, Nigeria. The 
tertiary institution is still a referral center for the neighboring north states: Kebbi, Niger and Zamfara. Data on the head and neck cancers from December, 2005 to December, 2010: age, sex, histological diagnosis and the site of the tumour origin were retrieved from the registers of the histopathology department which keeps archives of histology reports, microscopic slides and paraffin blocks of patients' biopsies that had been stored serially on yearly basis. Surgical tissue specimens are usually processed and stained by the Haematoxylin and Eosin method in the histopathology laboratory. The respective slides were retrieved and reviewed for diagnostic accuracy for cancer based on established microscopic criteria. The international classification of Disease for Oncology (ICD-O) third edition 2000 was used to classify the cancer based on site. The inclusion criteria are malignant tumours of the head and neck regions and the exclusion criteria are: benign tumors of the head and neck, tumors of the intracranial compartment and those cases in which both the slide and tissue blocks could not be traced.

The results were analyzed using statistical package for the social science version 17 and the result was compared with the similar published work undertaken in the same department by another researcher from 1999 to 2004, a five years retrospective study ${ }^{7}$.

The statistical test of significant difference in the results obtained from the two study periods was done using $\mathrm{Z}$ test (two tail test) with the level of significance was set at $5 \%$

\section{RESULTS}

One hundred and forty six head and neck cancers were studied representing $18.6 \%$ of the total number of 787 histologically diagnosed malignancies during the period. There were 93 males (63.7\%) and 53 female (36.3\%) with a male to female ratio of $1.8: 1$. The ages of patients ranged from 3-89 years with the mean age of $41.6 \pm 20.5$ years.
Majority of the patients (21.2\%) were within the ages of 51 to 60 years as shown in figure 1 . One hundred and twelve (76.7\%) of the cases seen were carcinomas, twenty (13.7\%) lymphomas, five (3.4\%) sarcomas and nine (6.2\%) blastomas as shown in figure 2 . Seventy cases (49.7\%) were Head and neck squamous cell carcinoma. Sinonasal carcinoma (16.4\%) was the commonest head and neck cancer others include: laryngeal (15.1\%), nasopharyngeal $(9.6 \%)$, salivary $(9.6 \%)$, and thyroid (8.9\%) carcinomas (figure 3 ). Retinoblastoma 5(3.4\%) was the commonest childhood head and neck cancer seen involving the eye and adnexae region.

\section{DISCUSSION}

Head and neck cancers have a global burden ${ }^{2,4,20}$. They are rated the $6^{\text {th }}$ most common type of cancer representing about $6 \%$ of all cases and accounting for an estimated 650,000 new cases and 350,000 cancer deaths worldwide every year and two third of these occurring in the developing conutries ${ }^{2}$. Various malignancies occur in the head and neck region ${ }^{2-5,} 7-11$. Studies in the developed world showed that squamous cell carcinoma accounted for 75-90 percent of the head and neck cancers ${ }^{1,15-17}$. In both western and local studies, most of head and neck cancers are associated with tobacco and alcohol use $e^{1,2,11}$.

In this study, 146 head and neck cancers accounted for $18.6 \%$ of the total number of histological diagnosed malignancies at the Usmanu Danfodiyo University Teaching hospital, Sokoto in North western Nigeria. Though the cancer registry was officially functional in 2002 with the services of a consultant, sometimes, for faster histological diagnosis, specimens are sent to other centres, coupled with the fact that some of the out patients with head and neck cancers declined examination under anaesthesia for sample to be obtained for histological diagnosis because of poverty or the former failed to bring back the histology report. Hence, this may also contribute to the nonsignificant change in the total number of patient during the study period as compared to the previous review were 131 histologically diagnosed head and neck cancers were seen over the period of 5 years ${ }^{7}$. The peak age for most head and neck cancers in the developed world is from $6^{\text {th }}$ decade of life ${ }^{1,12}$. This study, other studies in other parts of Nigeria and the previous review in this centre have showed the involvement of lower age groups: from $3^{\text {rd }}$ decade of life $e^{7,10,11,22}$. The reason(s) for the higher affectation of the younger age group in Nigeria are not so clear but may be attributed to race, genetics, unknown viral infection and nutritional deficiencies in diet and poverty in addition to cigarette smoking and alcohol consumption which are already known strong aetiological factors ${ }^{3,7}$. However, in the western world where most of the head and neck cancers occur from the $6^{\text {th }}$ decade of life and with the increasing evidence of role of the HPV type 16 and 18 in the pathogenesis of head and neck cancers especially for oropharyngeal cancers, younger age group were also being observed from $4^{\text {th }}$ decade of life ${ }^{1,2}$. Increasing number of young adults being affected coupled with the poorer prognosis in the black population $^{1,24}$ with head and neck cancers have a negative impact on social, political and economic development of any nation ${ }^{7}$, especially in developing nations such as Nigeria.

Our present study showed that the most common histological type were squamous cell carcinoma, which accounted for $47.9 \%$ of all malignancies which is similar to the findings in a previous study in which squamous cell carcinoma was the commonest and accounted for $30 \%$ of all the histologies ${ }^{7}$ and the other studies carried out in other parts of Nigeria ${ }^{7,9-11}$. However, contrary to our 
present finding, Amusa et al in 2005 on the pattern of head and neck tumours in a Nigeria teaching hospital-a ten year review, showed that lymphoma was the commonest histological type ${ }^{5}$. In our present study, Iymphoma was the $2^{\text {nd }}$ commonest which is similar to the findings of a previous study by Iseh et al in 2004 in the same locality ${ }^{7}$.

The present study also showed that Sinonasal region are the commonest site for head and neck cancers which is contrary to the studies reported in Sokoto, Lagos and Maiduguri previously where nasopharyngeal cancer was reported to be the commonest head and neck cancers ${ }^{7}$, 11,25 and for western countries, oral/oropharyngeal cancers were noted to be the commonest head and neck cancers ${ }^{8,21}$. The change in trend in our present study may be due to early presentation/diagnosis in relation to the patient(s) and the managing surgeon. However, Prospective studies are needed to identify the risk factors associated with Sinonasal cancers which may help to explain the high prevalence of Sinonasal cancers in our study.

Early recognition of symptoms and signs of squamous cell carcinoma of head and neck is important for prompt diagnosis ${ }^{12}$. Patients with early stage of head and neck cancers present with vague symptoms and minimal findings especially cancers involving the Sinonasal region and supraglottic part of the larynx ${ }^{2}$. In the developing world, patients with head and neck cancers usually have late presentation and advanced disease are common ${ }^{3}$. The findings in our study in order of occurrence; sinonasal (16.4\%), laryngeal (15.1\%) and nasopharyngeal/salivary gland $(9.6 \%)$ cancers, raises concern on the burden and management challenges of these cancers in our environment. There is a need to improve the socioeconomic status of the populace, create awareness for subtle signs and symptoms, and have high index of suspicion for early diagnosis and appropriate referral among our noble colleagues in other fields of specialization.

In conclusion, the study showed that cancers that presents with vague symptoms and minimal clinical signs at early presentation: sinonasal (16.4\%), laryngeal (15.1\%) and nasopharynx $(9.8 \%)$ are the commonest head and neck cancers with the younger adults mostly involved, which raise issues on the management challenges in our environment. There is no significant change in the proportion of patients with head and neck cancer $(Z=1.16$; $\mathrm{P}=0.25$ ) compared with a similar published work undertaken in the same department by another research from 1999 to 2004.

\section{REFERENCES}

1- Kim L, King T, Aguinik M. Head and Neck cancer; changing epidemiology and public health implication. Oncology. 2010;24:10

2- Marurs S, Forastiere AA. Head and neck cancers: changing epidemiology, diagnosis and treatment. MajoClin proc. 2008;83:489-501

3- Lilly-Tariah OB, Somefun AO, Adeyemo WL. Current evidence on the burden of Head and Neck cancers in Nigeria. Head and Neck Oncology 2009;1:14

4- Abdulhameed G, Saeed NM, Alkahiry W, Shukry S. Pattern of head and neck cancer in yemen. Gulf oncology. 2010;7:21-24

5- Amusa YB et al. Pattern of head and neck malignant tumours in Nigerian teaching hospital: a ten year review. West Afr J Med. 2004;23;280-5

6- Adoga A, Olubenga S. The challenges of managing head and neck tumors in a tropical tertiary health center in Nigeria. Pan Afr Med J.2011; 10:31

7- Iseh KR, Malami SA. Pattern of head and neck cancers in Sokoto-Nigeria. Nig J of otorhinolaryngology. 2006;3(2):77-83
8- Parkin DM, Bray F, Ferlay J, Pisani P. Global cancer statistic, 2002. CA Cancer J Clin. 2007;57:43-66

9- Ologe FE, Adeniyi KA, Busari SS. Clinicopathological study of head and neck cancers in ilori, Nigeria. Trop Doct. 2005;35(1):2-4

10- Otoh EC, Johnson NW, Dafillo IS, Adeleke OA, Olasoji HA. Primary head and neck cancers in Northeastern Nigeria. West afr J Med. 2004;23(4):305-313

11- Nwawolo CC, Ajekigbe AT, Oyeneyi JO, Nwankwo KC, Okeowo PA. Pattern of head and neck cancers among Nigerian in Lagos. West Afr J Med. 2001;20(2): 111-6

12- Argiris A, Karamouzis MV, Raben D, Ferris R. Head and neck cancer. The Lancet. 2008; 371(9625): 16951709

13- Mckaig RG, Baric BR, Olshan FA. Human papilloma virus and head and neck cancer; epidermiology and molecular biology. Journal of the science and specialities of the Head and Neck. 1998; 20(3); 250-265

14- Somefun OA, Nwawolo CC, Okeowo PA et al. Prognostic factors in the management outcome of carcinoma of the larynx in lagos. Niger postgraduate Med J. 2003; 10(2):103-6

15- Vineis $P$, Alavanja $M$, Buffler $P$, et al. Tobacco and cancer: recent epidemiology evidence. J Natl Cancer Inst. 2004;96:99-106

16- Blot WJ, McLaughlin JK, Winn DM, et al. Smoking and drinking in relation to oral and pharyngeal cancers. Cancer Res. 1988; 48:3282-3287

17- Tuyn AJ, Esteve J, Raymond L, et al. Cancer of the larynx/hypopharynx, tobacco and alcohol: IARC international case-control study in Turin and Varese(Italy), Zaragosa a nd $\mathrm{N}$ avarra (spain), Geneva(Switzerland) and Calvados(France). Int J Cancer. 1998;41:483-491

18- Hayat MJ, Howlader N, Reichman 
ME, Edward BK. Cancer statistic, trend and multiple primary cancer analyses from surveillance, epidemiology and end result program. Oncologist. 2007;12(1):20-37

19- Eniayejuni TA, Agoni M. A biometrics approach to population census and national identification in Nigeria: A prerequisite for planning and development. Asian Transaction on Basic and Applied Sciences. 2011;1(5):2221-4291

20- Chaudhry S, Khan AA, Mirza MK, et al. Estimating the burden of head and neck cancers in the public health sector of Pakistan. Asian Pacific J Cancer Prev. 2008;9:592532

21- Parkin DM, Pisani P, Ferlay J. Estimates of the worldwide incidence of 25 major cancers in 1990. Int J Cancer. 1990;80:827-841 22- Alabi BS, Badmus KD, Afolabi OA, Buhari MO, Segun-Busari S. Clinicopathological pattern of nasopharyngeal carcinoma in illorin, Nigeria. Niger J ClinPract. 2010;13:445-8

23- Nwaorgu O, kokong D, Onakoya P, Adoga S, Ibekwe T. Prevalence of human immunodeficiency virus seropositivity in head and neck malignancies in sub-Saharan Africa. ActaOto-laryngol. 2007;127:12181221

24- Rose BS, Jeong JH, Nath SK, Lu SM, Mell LK. Population-based study of competing mortality in head and neck cancer. J Clinoncol. 2011;29(26):3503-9

25- Ahmad BM, Pindiga UH. Malignant neoplasm of the ear, nose and throat in north eastern Nigeria. Highland Med Research J. 2004;2:45-48
Figure 1: Age distribution

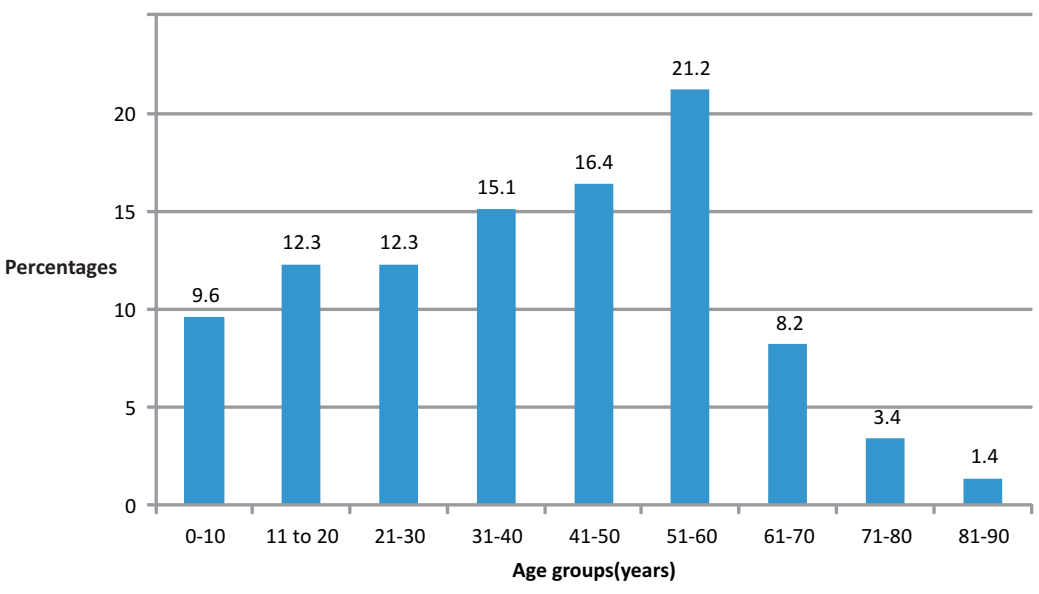

Figure 2: Comparison of the Histological types of malignant head and neck tumours

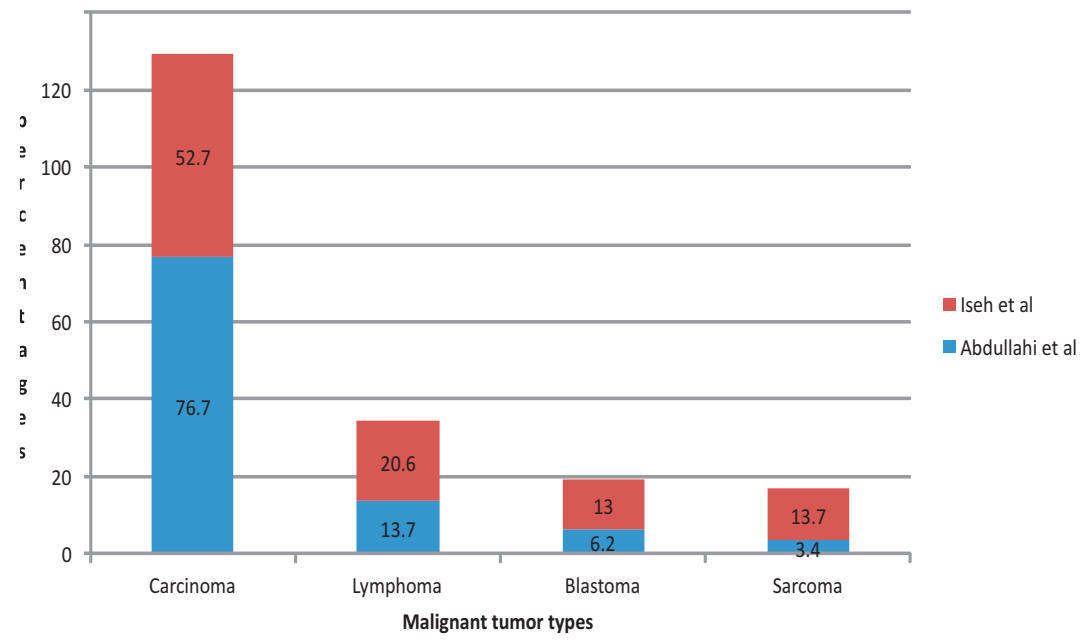

Figure 3: Anatomical site distribution of Head and Neck malignancies

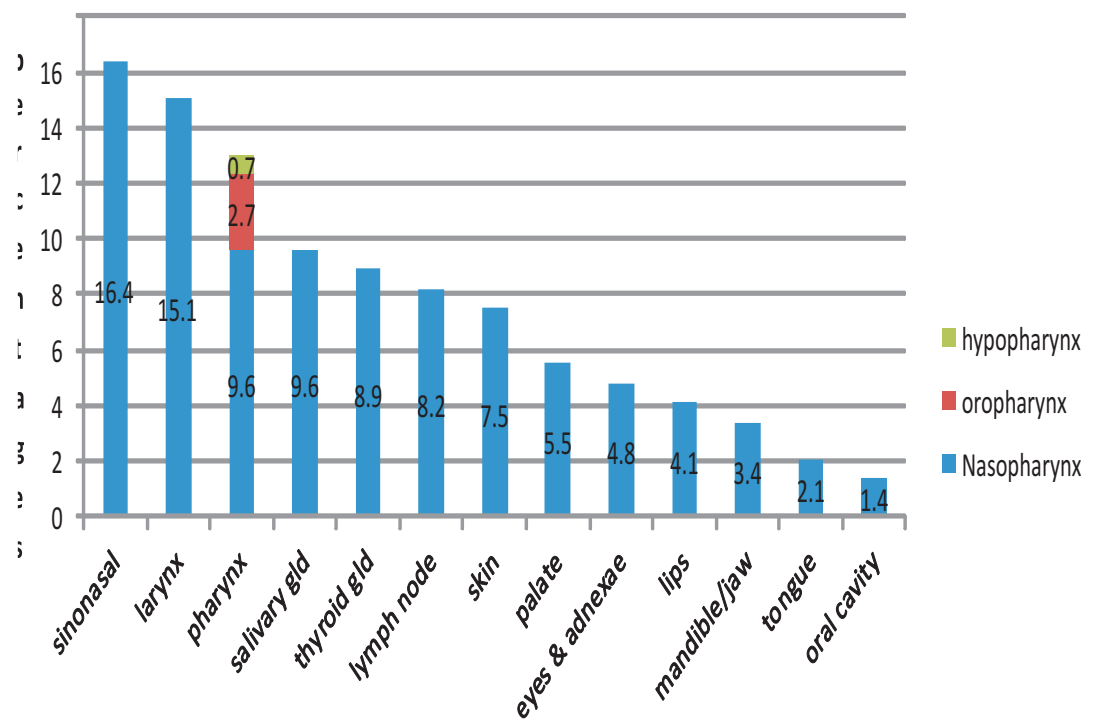

